\title{
Introduction: Creativity and Imagination through Time, Culture and Identity
}

\section{Tilly BLYTH, ${ }^{1}$ YAO Yan'an 姚燕安 ${ }^{2}$}

(Science Museum, London SW7 2DD, UK; School of Mechanical, Electronic and Control Engineering, Beijing Jiaotong University, Beijing 100044, China)

\begin{abstract}
Highlighting the Time, Culture and Identity cross-disciplinary project conducted between the Science Museum in London, the Palace Museum in Beijing, academics at Beijing Jiaotong University and the Institute for the History of Natural Sciences, and creative industries practitioners in China and the UK, this introduction highlights the key impacts of the research. As well as creating the practical output of a digital museum experience focused on the workings of the Country Scene clock, the research brought a range of wider impacts, including a change in understanding between collaborators, capacity-building skills, research process development and a change in attitude. The papers of this supplementary issue reflect some of the range of impacts of the work of our collaborators.
\end{abstract}

Keywords: Britain, China, eighteenth century, clocks, automatons, museum, creative industries, digital experience, impact

\section{Introduction}

$\mathrm{T}$ ime, Culture and Identity was a cross-disciplinary project ${ }^{3}$ bringing together historians, museum professionals, engineers, and creative practitioners in the UK and China. Our research considered the meaning of time, as embodied through a collection of exquisite clocks and automatons held at the Palace Museum in Beijing, and as reimagined through the creation of a new digital exhibit for the Science Museum in London.

Through these unique timepieces, the project aimed to explore the potential of the

Received: January 13, 2021. Revised: January 18, 2021.

1 Research interests: Museum and the creative industries; the visual culture of science, technology, and industry; and the history of information and information processing machines. Email: tilly.blyth@sciencemuseum.ac.uk

2 Research interests: Creative mechanism and machine design. Email: yayao@bjtu.edu.cn

3 https://www.sciencemuseumgroup.org.uk/project/time-culture-and-identity 
cultural and creative economy through two interacting strands:

1. A collaborative research program between curators, historians, and researchers at the Science Museum in London and the Palace Museum in Beijing, working with scholars at Beijing Jiaotong University and the Chinese Academy of Sciences's Institute for the History of Natural Sciences, focusing on the exceptional collection of seventeenth- and eighteenth-century clocks and automatons, manufactured and designed in Europe, and held at the imperial court in China.

2. A codesign approach to the digital interpretation of the clocks and automatons, involving the exchange of knowledge and creative practice between UK and Chinese creative businesses. This was underpinned by audience research into the display of the clocks in three locations-Beijing, Hong Kong, and London-and brought together creative design companies in both countries to explore new alliances and ways of working.

The timepieces at the heart of the project are more than just clocks; their moving parts animate figures and animals, whilst they play elaborate music that accompanies the animated scene. They form some of the most important treasures of the Palace Museum's national collection, reflecting a craftsmanship that not only highlights the significant skills in clock- and instrument-making in the seventeenth and eighteenth centuries but still enthralls audiences with the timepieces' beauty and magic today. Known as "singsongs" - or zimingzhong - these ornate artifacts tell us both about the history of design and craft skills in the UK and China, and also about the form and routes of international trade at the time.

By looking at the cross-cultural transmission of technology between Europe and China, Zhang (2012) has highlighted how these clocks were initially brought by European traders and missionaries in the seventeenth century and given to the Chinese emperor in order to gain his influence. The exquisite mechanisms and craftsmanship meant the devices quickly gained favor within the imperial court, enabling the emperor to both delight residents at the Forbidden City with these playful and complex mechanisms, and also express his authority and power through his ability to control time. Today, the mechanisms continue to intrigue and enchant visitors to the clock gallery of the Palace Museum, and when on loan to other museums, such as the Hong Kong Science and Technology Museum in 2019 and the Science Museum in London in 2021, they inspire transnational dialogue about the concept and ownership of time from multiple perspectives.

\section{The concept of time}

Time is a central tenet of the industrialized nation, through its effects on everyday routine, work, and efficiency (Thompson 1967), and the control of organized labor. The 
historian David Landes $(1983,1,7)$ has argued that the medieval creation of the mechanical clock contributed to turning Europe into a hegemonic aggressor, making "a civilization attentive to the passages of time, hence to productivity and performance." The dominance of a Western view of time across the globe did not just develop from the creation of precision timepieces, the development of the electronic telegraph, and official adoption in 1884 of a single standard of time around the world-Greenwich Mean Time. As Nanni (2012, xiii, 254) has shown in Australia and Africa, it was also the result of the creation of earlier imperial identities, through cultures that focused on concepts of work, order, and productivity, as well as ideas of progress and development. Wajcman (2015) has highlighted how, historically, the speed of the industrial age became synonymous with progress, driving a productivity-driven culture and a technologically-driven era of acceleration, so that today we find it hard not to feel "pressed for time."

In the Forbidden City the European zimingzhong sat in a rather unique position, presenting dials that usually showed Roman (I-XII) or Arabic (1-12) numerals and worked according to the twenty-four-hour European system of time. They can therefore be seen as a lens on the global dominance of Western time-from the clock to the seven-day week - and they begin to allude to the status of Western time as one of the most enduring, pervasive, and taken-for-granted legacies of colonialism in today's world.

But the clocks themselves do not just tell a simple story of the imposition of one culture's notions of time upon another. Instead they illuminate the deeply complex and interrelated ideas of time, showing how cultural and technological concepts were conegotiated, and how these were played out through the most powerful of influences on Chinese society, the emperor. At one level the clocks presented the emperor with a mechanism for control by presenting a Western model of time. But it was relatively straightforward to convert this model into the Chinese system of twelve double hours (shi chen), as both systems are divisible by twelve. So the two models of time, alongside other traditional systems of production such as "the sound of rooster" at daybreak, and the use of sundials and water clocks such as clepsydras, coexisted.

At another level the clocks also play out the complex transmission of technologies and cultures between the UK and China through their decorative design. Some show traditional rural scenes of idyllic English countryside, with cows and chickens amongst well-dressed shepherds. In others such representations are juxtaposed with the decorative style known as chinoiserie, including imagined images of the "East," such as turbaned figures, elephants, and palm trees. The designs reflect ideas about what was imagined to be popular for the Chinese market, and in themselves create their own unique aesthetic where the two imagined worlds collide. 


\section{Creating an audience experience}

Through our unique collaboration, the Time, Culture and Identity project created a series of outputs. These included workshops that brought together for the first time some of the pre-eminent academics working on these unique timepieces to share their archival research across the two countries (resulting in some of the papers in this supplementary issue); a new in-depth understanding of museum audiences' relationships to, and interests in, these historic automatons (TWResearch 2020); and a digital workshop (Figure 1) that brought together some of the leading museum and experience designers in the UK and China to explore methodologies for creative collaboration with museum objects (Science Museum 2020a).

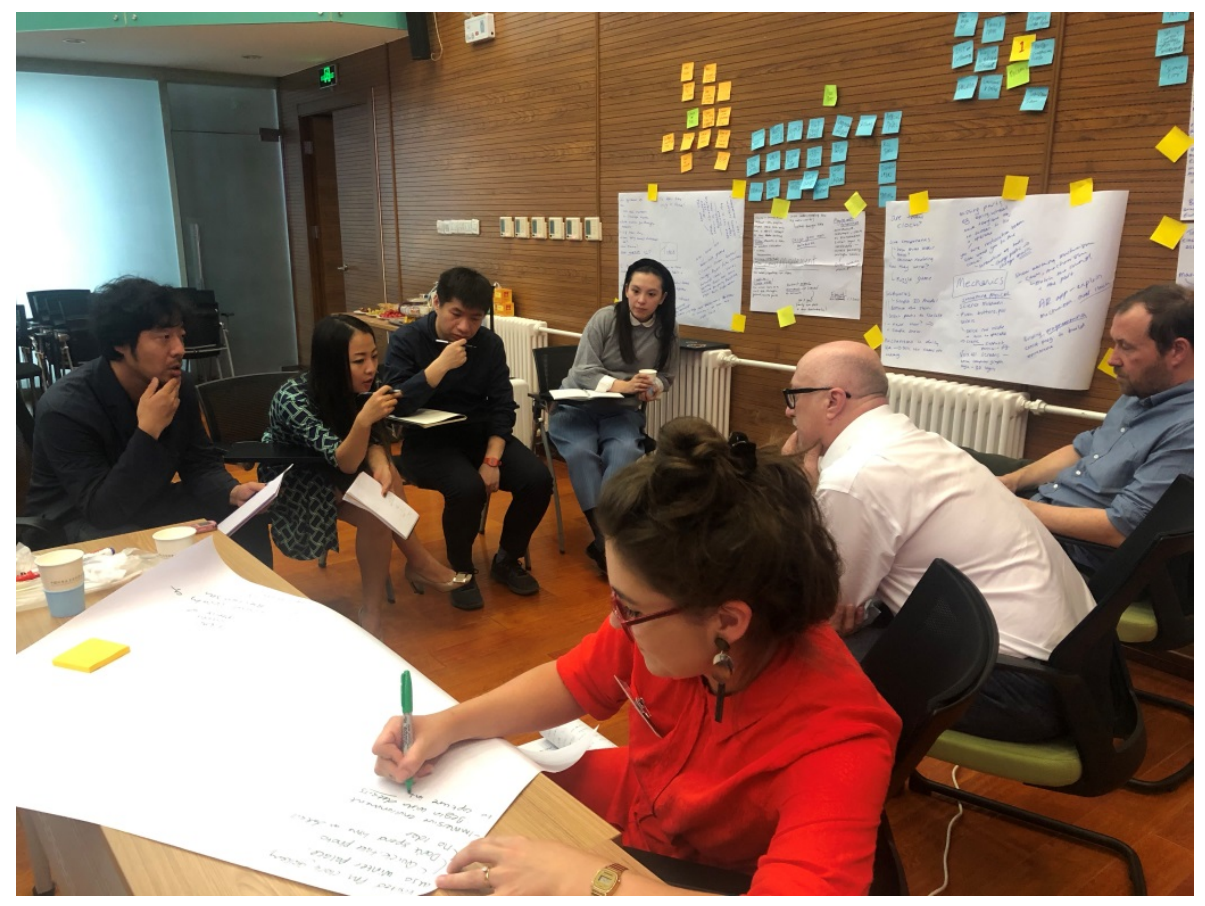

Figure 1: Creative professionals from the UK and China collaborating during the digital workshop. Courtesy of Science Museum Group.

The project also led to the development of a single creative product-a digital museum experience to be displayed as part of a larger exhibition on the zimingzhong at the Science Museum in London. The digital experience focused on the Country Scene clock (Figure 2), showing the movement of cow, sheep, pecking-chicken, and ladyspinning-yarn automatons, and revealing a serene English landscape in the base as it plays out its story. We also worked with engineering and computing experts at the Beijing Jiaotong University, so that the digital experience revealed our best 
understanding of the inner workings of the clock and automaton mechanisms, modeling how the cogs and wheels of the machine might work to produce the movement and music of the various parts.

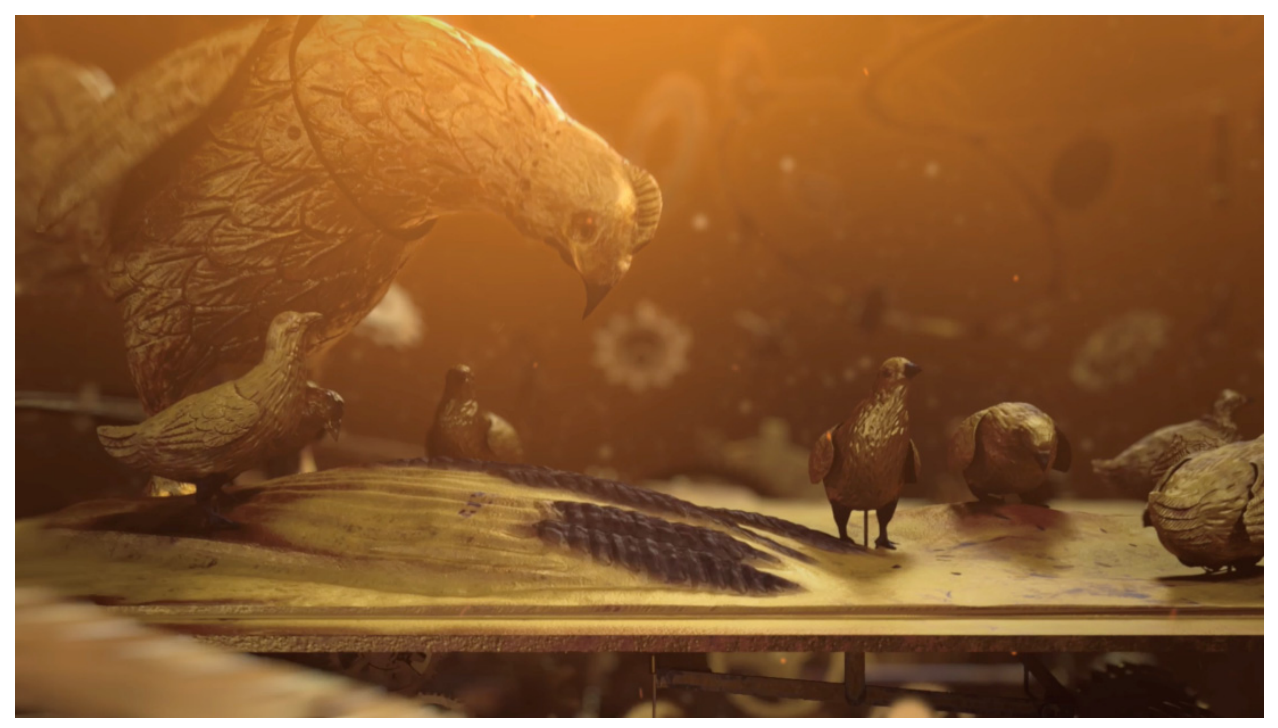

Figure 2: Still from the digital experience for the Country Scene clock. Courtesy of Science Museum Group/Blackbow.

Whilst this is a significant output in itself, the project's outputs were more than just the practical delivery of an experience for museum visitors. Just like the clocks themselves, the project also revealed the cultural interests, enthusiasms, and a collision of cultures across the UK and China in relation to much bigger themes - time, power, and the cosmos. For British audiences, it showed how the wonder of these historic artifacts comes, in part, from the craft of eighteenth-century making, with the ornate but surreal creations that emerged from a nascent relationship between the two countries. For Chinese audiences, the automatons reflect just one episode in an ongoing cultural fascination with much bigger ideas around the philosophy and science of measuring time, and time's enduring relationship to our cosmos.

\section{A creative collaboration}

All the papers in this supplementary issue bring their own unique perspective on the meaning of these complex technical objects. The first four papers focus on the objects themselves. Zhang Baichun looks at the craftsmanship of clockmaking as well as the devices themselves to discover how the skills of making were transmitted beyond the 
imperial court to the workshops of Guangdong and Suzhou. ${ }^{4}$ Roger Smith questions this established historical interpretation to show that these were not, as is commonly understood, diplomatic gifts shared at a state level, but were trade goods, used by Chinese customs officials who sent them to Beijing as part of their annual tribute to the emperor. As an esteemed conservator, Matthew Read invites us to look beyond the working object to the craftsmanship, cultures, and values embodied in a clock. He highlights the need for a conservator to have adaptability in thinking and approach, and the importance of recognizing the dynamic nature of objects such as these. $\mathrm{Li}$ Yezhuo, Chen Yu-Hsun, and Yan Hong-Sen focus on the movement of the object to explore the mechanisms of these rare devices and look at how we can reconstruct the workings of these ancient automatons when such historic devices cannot be accessed internally.

The next set of papers focus on a museological approach to the clocks, placing them in the context of the audiences and environments in which they will be enjoyed today. Carol Chung considers the relationship that museum audiences today have with these historical automatons of the imperial court, investigating audience connections through the quantitative and qualitative analysis of the Time, Culture and Identity project. The work highlights some interesting cultural differences, with more reverence for the objects in a museum and academic expertise in China, whereas in the UK audiences often appear to need more persuading that an object has relevance to them. UK audiences also appeared to find characters and people more engaging, whereas Chinese audiences were more enthused by the craftsmanship of the timepieces and the conservation work carried out for them. Our workshops to consider the creation of a digital exhibit also highlighted Chinese participants' interest in more abstract concepts, such as the philosophy and science of measuring time, compared to UK participants' interest in storytelling. The distinctive perspective of one of the creative professionals who was involved in these workshops is provided by Dominic Robson from Harmonic Kinetic, who applies his experience as an interaction designer and the tools of digital interpretation to these historical devices to open up audiences' imaginations to the possibilities and narratives of these rare historic machines.

As this selection of research papers prove, and Meagher and Martin (2017) have shown, research projects such as this rarely result in purely tangible instrumental impacts such as our "digital experience." Their influence also brings much broader impacts that are not so easily quantified.

4 According to the rule of CAHST, the Editors-in-Chief (Zhang Baichun and Jürgen Renn) are not allowed or encouraged to publish their papers in the journal. As this supplementary issue focuses on the research around the exhibition at the Science Museum, it requires a paper on the transfer of clock-making technology from Europe to China. Zhang's expertise positions him well to author a paper on this topic. Therefore, the journal has made an exception in this particular case. 
In this project, such a creative collaboration not only resulted in the instrumental impact of a new audience experience built on the basis of new models of clock mechanism, it also delivered a conceptual impact as collaborators developed a change in understanding about the nature and meaning of time, and the symbolism of the devices themselves within these different cultures. For the Science Museum in London and the creative businesses the museum worked with, the research helped with capacity building, enabling colleagues to develop new skills and understanding about working with Chinese collaborators. Ultimately, all the partners developed a better understanding of developing research processes with China, including digital connectivity through services such as WeChat (Science Museum 2020b).

Finally, perhaps the single most significant impact was the resulting change in attitude of the partners. We began the project asking how we could better understand the history and meaning of the clocks and what we can make collaboratively for museum audiences to engage them in these narratives. We completed the project reflecting on the role these timepieces have played, and continue to play, in the construction of UK and Chinese identities, values, and beliefs, and having developed an awareness of the multiple and contested meanings of time in different cultures.

Acknowledging these broader impacts of the research, the Time, Culture and Identity project not only acted to create a tangible digital experience for museum visitors. It was also an exploration of the long history of cultural and economic exchanges between the UK and China, and a practical example of this in the contemporary context-stimulating knowledge transfer between the cultural partners and brokering commercial relationships between UK and Chinese creative businesses. The research highlights the importance of the process of research for both public organizations such as museums, as well as commercial businesses, and calls for all parties to legitimize and support the time spent on research activities.

With this in mind, we are extremely grateful for the generosity and commitment of all our UK and Chinese partners in dedicating their time and enthusiasm to the research and for openly sharing their ideas and methods. We are excited for the new opportunities that have resulted from this collaboration and to reveal the digital experience at the Science Museum when the Zimingzhong exhibition opens, COVID-19 allowing, in the future.

\section{Acknowledgments}

The authors would like to thank colleagues at the Palace Museum in Beijing for their support for the project, and also at the Hong Kong Science and Technology Museum. In particular we would like to thank Professor Zhang Baichun 张柏春 for his generous support for this project and the kindness that he and his team showed throughout the 
development of our joint research. We would also like to thank Dr. Carol Chung, Dr. Li Yezhuo 李晔卓, Associate Professor Huang Xing 黄兴, and Ms. Emma StirlingMiddleton for their work delivering the project. Finally, we are grateful to the UK Arts and Humanities Research Council and the Newton Fund, whose support made this research possible.

\section{References}

Landes, D. 1983. Revolution in Time: Clocks and the Making of the Modern World. Cambridge, MA: Harvard University Press.

Meagher, L. R., and U. Martin. 2017. "Slightly Dirty Maths: The Richly Textured Mechanisms of Impact." Research Evaluation 26 (1): 15-27. Accessed January 12, 2021. https://doi.org/10. 1093/reseval/rvw024.

Nanni, G. 2012. The Colonisation of Time: Ritual, Routine, and Resistance in the British Empire. Manchester: Manchester University Press.

Science Museum. 2020a. "Time, Culture and Identity: A Digital Exchange Workshop: Summary Report." Accessed January 12, 2021. https://www.sciencemuseumgroup.org.uk/wpcontent/uploads/2020/02/tci-digital-workshop.pdf.

Science Museum. 2020b. "UK-China Collaboration in the Creative Industries: Reflections and Lessons Learned." Accessed January 12, 2021. https://www.sciencemuseumgroup.org.uk/ wp-content/uploads/2020/06/Time-Culture-Identity-Collaboration-guideline-A4-V6.pdf.

Thompson, E. P. 1967. “Time, Work Discipline and Industrial Capitalism.” Past and Present 38 (1): 56-97.

TWResearch. 2020. “Time, Culture and Identity audience research report." Accessed January 12, 2021. https://www.sciencemuseumgroup.org.uk/wp-content/uploads/2020/01/AudienceResearch-Summary.pdf.

Wajcman, J. 2015. Pressed for Time: The Acceleration of Life in Digital Capitalism. Chicago: University of Chicago Press.

Zhang, Baichun. 2012. "The Transmission of the European Clock-Making Technology into China in the 17th-18th Centuries." In Explorations in the History of Machines and Mechanisms, edited by T. Koetsier and M. Ceccarelli, 565-577. History of Mechanism and Machine Science, vol. 15. Dordrecht: Springer. Accessed January 12, 2021. https://doi.org/10.1007/978-94-007-4132-4_39. 